Leading article

\title{
Day surgery and gastroenterology
}

\begin{abstract}
Day surgery encompasses all surgical specialities and is an accepted mode of delivering surgical care. In the UK day surgery accounts for $30 \%$ of all elective surgical cases; this is expected to increase to $50 \%$ in the near future. ${ }^{1}$ In our institution the high level $(90 \%)$ of patient acceptability for day surgery has led to an increased patient demand for the service. Gastroenterological surgery, which includes endoscopy, constitutes a significant proportion of the current activity and promises to be the speciality that will contribute most to the predicted increase in day surgery. In this review we examine the reasons for the increase in day surgery, the adaptations required in providing a day surgery service, the types of gastroenterological procedures being performed, and finally those procedures that may be performed in the future.
\end{abstract}

\section{Increase in day surgery activity}

Day surgery has been practised in this country since the beginning of the century when it was recognised that there were psychological and medical benefits to be gained from early discharge from hospital. ${ }^{2}$ It was not until the 1970 s, however, that there was renewed interest in day surgery, when reports of the technical feasibility and benefits of day surgery were published by enthusiasts. ${ }^{3}$

The main reason for the present increase in day surgery is the allocation of additional resources for providing dedicated facilities and personnel by health services keen on promoting day surgery. This has been driven by economic considerations, as day surgery is thought to be more cost effective and efficient than inpatient treatment, thus allowing closure of some inpatient facilities. ${ }^{4}$ The cost per general surgical patient in our day care unit is $£ 471$ compared with $£ 571$ for an inpatient stay of 48 hours. This represents a saving of $21 \%$ which is achieved in a unit adapted from existing facilities. ${ }^{5}$ Therefore, careful planning is required if the purpose built day facilities are to achieve the desired levels of usage and efficiency to justify the considerable capital expenditure. ${ }^{6}$ The lack of training for personnel involved in providing day surgery services is being addressed with the opening of national training centres. Improvements in anaesthetic techniques and drugs have also contributed to the increased activity. However, recent developments in minimally invasive surgical technology have dramatically changed the practice of gastroenterology and will enable other procedures to be performed as day cases.

\section{Adaptations to current practice}

PREOPERATIVE ASSESSMENT

Effective preoperative assessment of patients thought suitable for day surgery is of paramount importance to its success. ${ }^{7}$ Patients requesting day surgery must have an appropriate surgical condition, be medically fit (ASA I or II), and have suitable social circumstances. In addition patients must be accompanied home by someone who is also available to assist them for the first 24 hours after surgery. In our unit, assessment is facilitated by the use of questionnaires which are completed by patients waiting to be seen at the day surgery clinic. Patients with an appropriate surgical condition are then interviewed by the liaison nurse who assesses their social circumstances, provides written information on the planned surgery, and explains the admission procedure. Should there be any doubts as to the medical fitness of the patient, an anaesthetic consultation is arranged. This preoperative assessment is essential for the safety of the patients undergoing surgery and ensures the smooth running of the unit by minimising late cancellations due to unforeseen medical or social problems.

\section{ANAESTHESIA AND SURGERY}

Considerable organisation is involved in the delivery of a successful day surgery service. ${ }^{9}$ Dedicated theatre lists are required so that the more complicated procedures can be performed in the morning to allow patients sufficient time to recover from surgery and be fit for discharge. Placing such patients on routine lists often leads to their delay or cancellation when inpatient procedures run over time.

The general anaesthetic agents used for day surgery must allow rapid postoperative recovery and minimal postoperative nausea. We have found that the use of locoregional anaesthesia has benefits which include eliminating the risks and side effects of general anaesthesia and providing better perioperative analgesia than narcotic analgesics.

Meticulous haemostasis is important as even slight bleeding provokes anxiety, which may prevent the patient from being discharged. ${ }^{10}$ Subcuticular sutures are used as they are more comfortable and do not need removing. Appropriate analgesia should be dispensed to patients on discharge to reduce the number of general practitioner home visits requested for postoperative pain control.

\section{POSTOPERATIVE CARE}

Day surgery services are increasingly being provided by purpose built day surgery units, which has substantially increased the number of day cases performed. ${ }^{11}$ The future requirement of postoperative nursing care in the community will be considerable as this trend of providing surgical services on an outpatient, day and short stay basis continues. The quality of these services, as measured by wound complication rates, will also have an impact on the amount of nursing care required for patients. ${ }^{10}$

The appropriate resources and identification of personnel for providing this postoperative care need to be addressed. We have found that there are benefits when this care is provided by nurses based with the day surgical unit which include: patient familiarity; continuity of care; audit data collection ${ }^{12}$; and specialist experience in the postoperative management of day surgery patients. 


\section{Day surgery procedures}

The gastroenterological procedures currently recommended for day surgery by The Royal College of Surgeons include diagnostic and therapeutic endoscopy, inguinal hernia repair, and treatment of peri-anal conditions. ${ }^{13}$ Gastroenterological conditions which once required open surgery are increasingly being performed laparoscopically. ${ }^{14-16}$ Laparoscopic access to the gastrointestinal tract overcomes two of the limitations of day surgery. It produces less postoperative physiological disturbance, enabling rapid recovery from surgery, and levels of postoperative pain which can be controlled with oral analgesia. ${ }^{17}$

Postoperative pain can be minimised by these less traumatic techniques ${ }^{18}$ and by identifying more effective and appropriate agents for pain control. We have shown the efficacy of oral analgesic regimens and local anaesthetic wound perfusion in hernia operations. ${ }^{19}$ Closer collaboration between specialities is needed if advances in this area are to be achieved. The other important limitation to day case surgery is the risk of occasional severe postoperative complications. Admission of patients at risk after surgery to supervised hotel-type accommodation close to the hospital may help overcome this particular problem.

\section{ENDOSCOPY}

Diagnostic upper gastrointestinal endoscopy is considered by most specialists as an outpatient procedure and it constitutes a significant proportion of the workload of many day surgery units. ${ }^{20}$ Provision of adequate endoscopy facilities and the elimination of sedation for most patients undergoing diagnostic upper gastrointestinal endoscopy would reduce the inappropriate use of day care facilities for these cases. Colonoscopy is an uncomfortable experience for which most patients require sedation with or without analgesia and recovery facilities, usually in a day unit.

Therapeutic endoscopy has reduced the need for surgery in the treatment of benign and malignant conditions of the upper and lower gastrointestinal tract. Procedures which can be performed on a day basis include treatment of benign strictures of the oesophagus and rectosigmoid region with pneumatic or rigid endoscopic dilatation. ${ }^{21}$ In addition, intubation, laser therapy, and diathermy have replaced palliative procedures aimed at allowing patients to swallow for advanced lower oesophageal and gastric malignancies. ${ }^{22}$ The insertion of percutaneous endoscopic gastrostomies (PEG) for enteral feeding ${ }^{23}$; stenting of benign and malignant biliary strictures with the side viewing endoscope ${ }^{24} 25$; and colonoscopic polypectomy can also be safely treated on a day basis. ${ }^{26}$ As the infrastructure for providing postoperative care in the community improves more of these procedures can be performed safely as day cases. Some patients particularly the elderly with general debility and associated medical problems will need postoperative care in short stay facilities.

\section{ANORECTAL CONDITIONS}

Minor perianal conditions which are currently treated as day case procedures include lateral subcutaneous sphincterotomy for anal fissure, fistulectomy, and closed haemorrhoidectomy. ${ }^{27}$ Acute conditions such as drainage of perianal abscess and thrombosed external haemorrhoids are often treated late in the evening on emergency lists and are therefore admitted overnight for observation. There are reports of more extensive procedures being performed as day cases under loco regional anaesthesia. These include procedures for repair of rectovaginal fistula, posterior anal canal repair for incontinence, procedures for rectal prolapse, and microscopic resection of rectal carcinoma. ${ }^{28}$ The postoperative management for these procedures is relatively straightforward and given appropriate social circumstances, can generally be managed at home by trained community nurses.

\section{HERNIAS}

There is a high prevalence of groin hernias in the community and they constitute a significant proportion of the surgical workload. There are numerous reports of the feasibility of day surgery for inguinal herniorrhaphy ${ }^{29}$ and this procedure accounts for between $15-20 \%$ of our own day case workload. ${ }^{12}$ In addition, paraumbilical, epigastric, incisional, and femoral hernias are also repaired as day cases, with the exclusion of particularly large hernias or morbidly obese patients.

There is still a reluctance on the part of surgeons to perform day case inguinal herniorrhaphy. In most health regions only $10 \%$ of inguinal hernias, excluding paediatric cases, are performed as day cases. ${ }^{30}$ There is therefore considerable scope for an increase in day case herniorrhaphy. In specialist centres, the Shouldice and Lichtenstein procedures for day case inguinal herniorrhaphy produce recurrence rates of less than $1 \%$ with minimal morbidity and mortality. The efficacy and safety of laparoscopic hernia repair needs to be determined in a randomised controlled trial before it can be recommended as a day case procedure.

\section{LAPAROSCOPIC SURGERY}

The use of laparoscopic surgery has revolutionised gastroenterological surgery. Laparoscopy was initially practised by gynaecologists, who performed a limited number of diagnostic and therapeutic procedures. Improvements in optical systems and the rapid development and refinement of instruments has allowed procedures such as cholecystectomy to be performed laparoscopically. ${ }^{31}$ The procedure has popularised laparoscopic surgery worldwide, and inspired surgeons to perform a wide range of gastroenterological surgery using these techniques, from hernia repair to total colectomy. ${ }^{32}$ In the US, economic constraints has resulted in day case cholecystectomy, appendicectomy, inguinal herniorrhaphy and feeding jejunostomy. ${ }^{33-36}$

The higher morbidity and mortality arising from laparoscopic rather than standard cholecystectomy emphasises the need for proper training of surgeons and appropriate selection of procedures suitable for minimally invasive surgery. ${ }^{37}$ Otherwise this potentially valuable technique could be discredited and its development retarded. Diagnostic laparoscopy has also benefited from the publicity generated by laparoscopic cholecystectomy. There has been a renewed interest in its role in the diagnosis of non-specific abdominal pain and replacing laparotomy in the assessment of the acute abdomen. ${ }^{38}$ It is also of benefit in the staging of malignancies including lymphoma and oesophageal and gastric carcinoma. ${ }^{39} 40$ The advantages of a combined endoscopic and laparoscopic approach to gastrointestinal pathology is under current evaluation.

\section{Conclusion}

In the UK regional health boards are promoting day surgery because of the reported economic benefits of short stay surgery. However, careful planning of purpose built facilities and training of day surgery staff is required if this 
is to be realised. The aim of providing safe and effective services can be achieved with strict adherence to the guidelines and audit of day surgery. The development of dedicated day surgery facilities has resulted in a high level of patient acceptability and in turn resulted in a patient led demand for day surgery. Gastroenterological day case surgery will continue to increase with experience in loco regional anaesthesia and as minimally invasive techniques are deemed to be safe and effective.

\section{FENTON-LEE E RIACH}

University Department of Surgery, T G COOKE

Glasgow Royal Infirmary,

Glasgow G31 2ER

Correspondence to: Professor T G Cooke.

Keywords: day care surgery, gastroenterology, day care.

1 Audit Commission. A short cut to better services. Day surgery in England and Wales. London: HMSO, 1990.

2 Nicoll JH. The surgery of infancy. BMF 1909; ii: 753-6.

3 Ruckley CV, MacLean M, Smith AN, Small WP, Falconer CWA. Team approach to early discharge and outpatient surgery. Lancet 1971 ; ii: $177-80$.

4 Russell IT, Devlin HB, Fell M, Glass NJ, Newell DJ. Day case surgery for hernias and haemorrhoids. A clinical, social, and economic evaluation. Lancet 1977; i: 844-9.

5 Young D. Economic evaluation of day surgery. Glasgow: Strathclyde University, 1993: 45. (Dissertation.)

6 Fenton-Lee D. Help design a day surgery unit - a surgeon's ideas. Fournal of One Day Surgery. 1993; 2: 7-9.

Ogg TW. An assessment of postoperative outpatient cases. BMF 1972; 4: 573-6.

Rudkin GE, Osborne GA, Doyle CE. Assessment and selection of patient for day surgery in a public hospital. Med $\mathcal{f}$ Aust 1993; 158: 308-12.

9 Ruckley CV, Maclean M, Ludgate CM. Major outpatient surgery. Lancet 1973; ii: 1193-6.

10 Fenton-Lee D, Baxter JN, Riach ET, Cooke TG. Clinical implications of wound complications in day case surgery. Irish $\mathcal{F}$ Med Sci 1992; 161 (suppl 11): A51.

11 Audit Unit. Day surgery in Scottish hospitals. Edinburgh: The Scottish Office 1992.

12 Fenton-Lee D, Riach E, Cooke TG. Day surgery audit. Gut 1993; 34 (suppl 1): $\$ 27$.

13 The Royal College of Surgeons of England. Commission on the provision of surgical services. Report of the working party on guidelines for day surgery. London: Royal College of Surgeons, 1992: 7, 14

14 Pellegrini C, Wetter LA, Patti M, Leichter R, Mussan G, Mori T, et al. Thorascopic esophagomyotomy. Initial experience with a new approach for the treatment of achalasia. Ann Surg 1992; 216 (3): 291-6.
15 Rogers DA, Lobe TE, Schropp KP. Evolving uses of laparoscopy in children. Surg Clin North Am 1992; 72: 1299-313.

16 Falk PM, Beart RW, Wexner SD. Laparoscopic colectomy: a critical appraisal. Dis Colon Rectum 1993; 36: 28-34.

17 McMahon AJ, Baxter JN, Anderson JR, Ramsay G, Gallaway D, Russell IT, et al. Assessment of pain after laparoscopic cholecystectomy and minicet al. Assessment of pain after laparoscopic

18 Royal College of Surgeons of England, College of Anaesthetists. Commission on the provision of surgical services. Report of the working party on pain after surgery. London: Royal College of Surgeons, 1990

19 Fenton-Lee D, Riach ET, Kenny G, Murray G, Robertson K, Cooke TG. Local anaesthetic wound perfusion in day case hernia repair. Proceedings of the British Association of Day Surgery meeting. Cambridge 1993.

20 Audit Commission. A short cut to better services: day surgery in England and Wales. London: HMSO, 1990.

21 Kozarek RA. Hydrostatic balloon dilatation of gastrointestinal stenoses: A national survey. Gastrointest Endosc 1986; 32: 15-9.

22 Carter R, Smith JS, Anderson JR. Prospective randomised controlled trial of endoscopic intubation and laser recanalisation in the treatment of malignant dysphagia Br f Surg 1990; 77: 1412 .

23 Ponsky JL, Gauderer MWL, Stellato TA. Percutaneous endoscopic gastrostomy: Review of 150 cases. Arch Surg 1983; 118: 913-4.

24 Soehendra N, Rynders-Frederix V. Palliative bile duct drainage: A new endoscopic method of introducing a transpapillary drain. Endoscopy 1980; 12: 8

25 Geenen DJ, Geenen JE, Hogan WJ, Schenck J, Venu RP, Johnson GK, Jackson A. Endoscopic therapy for benign duct strictures. Gastrointest Endosc 1989; 35: 367-71.

26 Forde KA. Colonoscopic management of polypoid lesions. Surg Clin North Am 1989; 69: 1287-308.

27 Khubchandani I, Trimpi H, Sheets JA. Closed haemorrhoidectomy with local anaesthesia. Surg Gynecol Obstet 1972; 135: 955-7.

28 Marti MC. Ambulatory proctologic surgery. Ther Umsch 1992; 49: 489-92.

29 Glasgow F. Short stay surgery (Shouldice technique) for repair of inguinal hernia. Ann R Coll Surg Engl 1976; 58: 133-9.

30 Audit Commission. All in a day's work: An audit of day surgery in England and Wales. London: HMSO, 1992.

31 Mouret G. From the first laparoscopic cholecystectomy to the frontiers of laparoscopic surgery: the future perspectives. Dig Surg 1991; 8: 124-5. 32 Harvey M, Cahill J, Wastell C. Laparoscopic general surgery. Br f Hosp Med 1992; 47: 655-62.

33 Reddick EJ, Olsen DO. Outpatient laparoscopic laser cholecystectomy. Am f Surg 1990; 160: 485-9.

34 Albrink MH, Foster J, Rosemurgy AS, Carey LC. Laparoscopic feeding jejunostomy: also a simple technique. Surg Endosc 1992; 6: 259-60.

35 McAnena OJ, Austin O, O'Connell PR, Hederman WP, Gorey TF, Fitzpatrick J. Laparoscopic versus open appendicectomy: a prospective

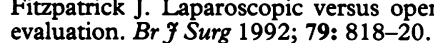

36 Macintyre IC. Laparoscopic herniorrhaphy. Br $\mathcal{F}$ Surg 1992; 79: 1123-4. Macintyre IMC,

38 Easter DW, Cuschieri A, Nathanson LK, Lavelle-Jones M. The utility of diagnostic laparoscopy for abdominal disorders. Audit of 120 patients. Arch Surg 1992; 127: 379-83.

39 Lightdale CJ. Laparoscopy for cancer staging. Endoscopy 1992; 24: 682-6. 40 De Vita VT, Bagley CM, Goodell B, et al. Peritoneoscopy in the staging of Hodgkin's disease. Cancer Res 1971; 31: 1746-50. 